\title{
Necessity of Telemedicine
}

\author{
Sedigheh Mirhashemi, ${ }^{1,}$ Hamid Reza Rasouli, ${ }^{1}$ and Amir Hossein Mirhashemi ${ }^{2}$ \\ ${ }^{1}$ Trauma Research Center, Baqiyatallah University of Medical Sciences, Tehran, IR Iran \\ ${ }^{2}$ School of Dental Medicine, Tehran University of Medical Sciences, Tehran, IR Iran \\ ${ }^{*}$ Corresponding author: Sedigheh Mirhashemi, Trauma Research Center, Baqiyatallah University of Medical Sciences, P. O. Box: 1994943636, Tehran, IR Iran. Tel: +98-2188053766, Fax: \\ +98-2188053766, E-mail: sedmir54@yahoo.com
}

Received 2014 November 26; Revised 2015 January 19; Accepted 2015 February 2.

Keywords: Telemedicine, Trauma, Health

\section{Dear Editor,}

Telemedicine has been defined as the use of telecommunication technologies like e-mail, wireless tools, and other applications to diagnose and treat a patient's clinical health status. Different types of services can be provided by telemedicine, such as home telehealth and referral to medical centers.

There have been several examples of large-scale disasters over the last few decades with various causes. One of the first applications of telemedicine in a disaster situation was done 18 years ago following an earthquake in Armenia (1). Moreover, several studies support the costeffectiveness, clinical feasibility, and diagnostic accuracy of telemedicine in the acute phase response to disasters (2). In 2003, although a large part of the city was destroyed the Bam earthquake, emergency medical interventions did not respond timely or adequately. Hence, we need a generalized and appropriate management plan to prepare in untimely events. Telemedicine can provide coordination between various governmental and international agencies as well as NGOs. However, the effectiveness of telemedicine depends on the data transfer rate and the interaction between the individuals involved (3). Response to a disaster situation has three phases; namely the acute phase response (immediate post-disaster period), subacute disaster response (days to weeks following the disaste), and disaster recovery (months to years) phase (4).

In Iran, we need an alternative control and management plan to treat endangered people immediately. Effective information management and communication is absolutely necessary to generate coordinated actions and prevent or treat serious health problems resulting from -onset disasters acutely. Telemedicine, in particular, has been shown to be effective in improving management of emergencies in pre-hospital care. While telemedicine can be utilized in the hospital setting, its implementation is similar to traditional telemedicine systems. We have identified pre-hospital telemedicine as a weak area that holds great promise for medical care treatment. The new family medicine plan of the ministry of health for improved performance of such plans aim to address and implement the concepts and capabilities of telemedicine nationally (5). Telemedicine can be a powerful tool when a reduction in patient transports is combined with improved care of those transported. The aim of this new plan is easy access to public health care and enhancing the quality of healthcare services rendered. In a country like Iran, with its under-developed transportation network, dispersion of the population in various remote areas (which are difficult to access), and the problem of population aging which make the uniform medical health service delivery difficult, telemedicine can provide more expedient and more accurate diagnosis of patients, in provide tentative decisions regarding their treatment, reduce the loss of golden time and cost reduction. Telemedicine promises unique opportunities for both patients and clinicians when implemented in direct response phase following crises or disasters.

\section{Acknowledgments}

The authors are grateful to Professor M.H.K. Motamedi for his editorial support.

\section{Footnote}

Authors' Contribution:Study concept design, acquisition of data, and drafting of the manuscript: Sedigheh Mirhashemi, Hamid Reza Rasouli, and Amir Hossein Mirhashemi.

\section{References}

1. Merrell RC, Doarn CR. Disasters--how can telemedicine help? 


\section{Mirhashemi S et al.}

Telemed J E Health. 2005;11(5):511-2. doi: 10.1089/tmj.2005.11.511. [PubMed:16250812]

2. Balch D. Developing a National Inventory of Telehealth Resourc es for Rapid and Effective Emergency Medical Care: a white paper developed by the American Telemedicine Association Emergency Preparedness and Response Special Interest Group. Telemed JE Health. 2008;14(6):606-10. doi: 10.1089/tmj.2007.0127. [PubMed: 18729762]

3. Mirhashemi S, Ghanjal A, Mohebbi HA, Moharamzad Y. The 2003
Bam earthquake: overview of first aid and transport of victims. Prehosp Disaster Med. 2007;22(6):513-6. [PubMed:18709939]

4. Simmons S, Alverson D, Poropatich R, D'Iorio J, DeVany M, Doarn CR. Applying telehealth in natural and anthropogenic disasters. Telemed J E Health. 2008;14(9):968-71. doi: 10.1089/tmj.2008.0117. [PubMed:19035809]

5. Salehahmadi Z, Hajialiasghari F. Telemedicine in iran: chances and challenges. World J Plast Surg. 2013;2(1):18-25. [PubMed: 25489500] 